\title{
Clinical and Radiographic Outcomes of Cervical Open-Door Laminoplasty Withmodified Centerpiece Mini-Plate Fixation and Extensor Attachment Point Reconstruction in Treating Cervical Spondylotic Myelopathy
}

Fa-jing Liu

Tianjin Hospital

Yan-cheng Liu

Tianjin Hospital

Ze-pei Zhang

Tianjin Hospital

Jun Miao ( $\triangle$ miaojun0707@163.com )

Tianjin Hospital

Research article

Keywords: cervical spondylotic myelopathy, open-door laminoplasty, centerpiece titanium plate, axial symptoms

Posted Date: February 25th, 2021

DOl: https://doi.org/10.21203/rs.3.rs-242053/v1

License: (c) (1) This work is licensed under a Creative Commons Attribution 4.0 International License. Read Full License 


\section{Abstract}

Objective

This retrospective study aimed to investigate the clinical and radiographic outcomes of open-door laminoplasty with modified centerpiece mini-plate fixation and extensor attachment point reconstruction for treating cervical spondylotic myelopathy (CSM).

Method

Sixty-nine patients with CSM, who underwent C3-7 open-door laminoplasty in our hospital from January 2016 to May 2017, were divided into two groups: group A underwent surgery with a modified centerpiece titanium plate and group $B$ underwent surgery with a conventional centerpiece titanium plate. Changes in cervical spinal angle (CSA), cervical range of motion (ROM), atrophy of posterior cervical muscles, and neurological function (Japanese Orthopaedic Association [JOA] score) and the occurrence of axial symptoms (AS) were compared between the groups.

Result

There were no significant differences in operative time, intra-operative blood loss, lamina open angle, and spinal cord drift distance between the groups. After the surgery, JOA score significantly increased $(\mathrm{P}<$ $0.05)$, neurological recovery rates were similar $(62.7 \%$ vs. $63.4 \%)$, cervical ROM did not significantly change when compared with the preoperative level $(P>0.05)$ in both groups; CSA and cross-sectional area of the posterior cervical muscles decreased significantly in group $B(P<0.05)$ but not in group $A(P>$ $0.05)$, and postoperative AS were significantly more severe in group $B$ than in group $A(P<0.05)$.

Conclusion

Open-door laminoplasty is an effective surgical procedure for CSM. The application of modified centerpiece mini-plate fixation effectively reconstructs the posterior extensor attachment points, which reduces posterior cervical muscle atrophy, maintains cervical curvature, and reduces the occurrence of axial symptoms.

\section{Background}

Cervical spondylotic myelopathy (CSM) is a common degenerative spinal disease. The main pathogenic factors include disc herniation, hyperplasia of posterior osteophytes, ossified posterior longitudinal ligament, and ligamentum flavum thickening, which can compress the spinal cord and cause varying degrees of neurological impairment [1]. CSM patients with severe spinal cord compression or multisegmental compression ( $\geq 3$ levels) are often treated surgically with a posterior cervical approach. Opendoor laminoplasty is a classic posterior decompression technique that has numerous advantages including relative simplicity, short learning curve, adequate spinal cord decompression, less loss of cervical motion segments, and relatively complete cervical spinal canal after surgery [2-3]. 
With the development and clinical application of various types of internal fixation devices, vertebral laminar fixation in open-door laminoplasty has gradually transferred from the initial silk suspension to suture anchor fixation and the current titanium mini-plate fixation, with the centerpiece titanium plate being the most representative among the many titanium mini-plates available for use [3-4]. Compared with the first two fixation methods, fixation strength of the titanium mini-plate is the greatest which provides overwhelming advantages in terms of immediate stability, promoting bony fusion, and maintaining long-term cervical spine stability $[3,5]$.

During laminoplasty, the posterior cervical extensor muscles are dissected extensively. In patients with a short muscular neck, partial dissection of the semispinalis cervicis off of its C2 spinous process attachment is required in order to allow adequate opening of the vertebral laminae [6]. In addition, the removal of the spinous process before vertebral lamina opening also leads to the loss of a wide range of muscle attachment points, resulting in postoperative posterior cervical muscle atrophy, which further weakens the effect of anti-axial load and stretch stress and may lead to changes in the cervical curvature, decreased cervical stability, and increased incidence of postoperative axial symptoms [7-8].

In order to reconstruct the muscle attachment points, we have modified the two-hole centerpiece titanium plate by adding a hole to the laminar side of the plate to allow direct suturing of the posterior cervical extensor muscles to the plate. Conventional centerpiece titanium plate could not provide attachment points for the muscles. The muscles on both sides were often stitched end-to-end when stitching the incisions, which causes muscle-skeletal separation. Nevertheless, the modified centerpiece titanium plate could provide effective muscle attachment points for the key muscles, such as semi spinaliscervicis, trapezius, erector spinae, splenius capitis, and splenius cervicis. In this study, we compare the clinical efficacy between our technique and conventional laminoplasty with a standard centerpiece titanium plate and muscle closure.

\section{Materials And Methods}

\section{Patients}

The clinical data of 69 patients with CSM who underwent C3-7 open-door laminoplasty in Tianjin Hospital from January 2016 to May 2017 were retrospectively analyzed. Patients were divided into two groups: group A (37 patients) underwent surgery with the modified centerpiece titanium plate that allowed muscle suturing to the plate and group B (32 patients) underwent surgery using the conventional centerpiece plate. There were no significant differences in gender, age, disease course, follow-up period, ratio of increased signal intensity in the spinal cord, and types of pathology between the groups $(P>$ 0.05) (Table 1).The study was approved by the Medical Ethics Committee of Tianjin Hospital. All patients provided written informed consent.

Inclusion and exclusion criteria 
Patient inclusion criteria were as follows: (1) symptoms and signs of typical CSM; (2) normal cervical curvature and spinal cord compression at $\geq 3$ levels; and (3) clinical and radiographic follow-up of at least 12 months. We excluded patients with coagulation disorders, concurrent thoracic or lumbar spinal stenosis, multi-level cervical instability, cervical kyphosis, OPLL, tumor, fracture, or infection.

\section{Surgery}

After induction of general anesthesia, the patient was placed in the prone position with the head fixed in a Mayfield head frame and the neck slightly flexed. A posterior midline incision was made to dissect through the center of the nuchal ligament and expose the spinous processes. The posterior cervical muscles were then detached from the subperiosteum on both sides of the spinous process to expose the vertebral laminae and lateral masses. A $3 \mathrm{~mm}$ diameter high-speed drill (Stryker, USA) was used to create bilateral slots at the line of transition between the vertebral laminae and lateral masses. The side with fewer or less severe symptoms was used as the hinge side and the cortex inside the vertebral lamina was retained. The side with more or more severe symptoms was used as the open side and the medial and lateral cortex of the vertebral lamina was removed. The spinous process was trimmed to the appropriate length and the ligamentum flavum between the $\mathrm{C} 2 / 3$ and $\mathrm{C} 7 / \mathrm{T} 1$ vertebral lamina was separated. After clamping the root of the spinous process, the lamina was slowly opened to $35^{\circ}-45^{\circ}$.

In group A patients, at C3, C4, and C7, modified centerpiece titanium plates (Beijing Fule Medical Equipment Co., Ltd.) of appropriate length were selected to support and fix the vertebral laminae to the lateral masses (Figure 1C); the remaining segments were fixed with conventional titanium plates. Screws with a length of 6 and $8 \mathrm{~mm}$ were used to fix the plates to the lamina and lateral mass, respectively. The stripped semispinalis cervicis and multifidus muscles were sutured to the reserved additional hole of the C3 titanium plate, and the remaining posterior cervical muscles were sutured to the reserved additional hole of the plates at other levels (Figure 1E). In group B patients, conventional centerpiece titanium plates (Medtronic Sofamor Danek, USA) were used for fixation and the posterior cervical muscles and fascia layers were sutured to the corresponding contralateral layer (Figure 2).

All patients received prophylactic antibiotics and $40 \mathrm{mg}$ of methylprednisolone for 3 days. Surgical drains were removed when the drainage volume decreased to less than $30 \mathrm{~mL} / 24$ hours. All patients were allowed to perform out-of-bed activities with neck support.

\section{Evaluation criteria}

The 17-point Japanese Orthopaedic Association (JOA) scoring system was used to evaluate neurological recovery before and after surgery [1]. Recovery rate was calculated as follows: (postoperative score preoperative score) $/(17$-preoperative score $) \times 100 \%$. Axial symptoms $($ AS) were recorded as postoperative neck pain with neck stiffness or shoulder stiffness, or both. Postoperative AS were evaluated according to Hosono et al [9]. and graded as severe (analgesic or local injection regularly required), moderate (physiotherapy or therapeutic compress regularly required), or mild (no treatment required). 
Cervical curvature was evaluated by the cervical spine angle (CSA) using Harrison's method [10]: two lines were drawn parallel to the vertebral posterior margins of C2 and C7 and CSA was defined as the angle between the intersection of the two lines (Figure 1A,1F). Cervical range of motion (ROM) was measured as follows [11]: the trailing edge lines at $\mathrm{C} 2$ and $\mathrm{C} 7$ were measured in the flexion and extension positions with $a_{1}$ representing the flexion position and $a_{2}$ the hyperextension position; ROM was defined as $a_{1}+a_{2}$. Spinal drift distance(d) was defined as the difference between the postoperative (d2) and preoperative distance (d1) between the posterior superior edge of the $\mathrm{C} 5$ vertebrae and the anterior edge of the spinal cord on the midline image of sagittal magnetic resonance imaging (MRI) [12] (Figure 1B,1G). Lamina open angle (a) was defined as follows: in the cross-sectional computed tomography image of each vertebral body, the angle between the point line of the medial facets and the line of the portal axis and the edge of the open lamina was measured; $a=\left(a_{3}+a_{4}+a_{5}+a_{6}+a_{7}\right) / 5$ (Figure 1D) [13]. Cross-sectional area of the posterior cervical muscles, including the trapezius, splenius capitis, semispinalis capitis, semispinalis cervicis, multifidus, longissimus capitis, longissimus cervicis, levator scapulae, posterior scalene, medial scalene, and anterior scalene, were measured at $\mathrm{C} 3 / 4$ and $\mathrm{C} 4 / 5$ on transverse MRI using Auto CAD software (Autodesk Inc., San Rafael, CA, USA) [7,14] (Figure 1H). To ensure measurement accuracy, two independent radiologists evaluated the images and each parameter was measured three times and averaged.

\section{Statistical analyses}

Statistical analyses were conducted using SPSS software version 20.0 (IBM, Chicago, IL, USA). Repeated measures at different time points were compared by repeated measures analysis of variance (RT-ANOVA). Continuous variables were compared between groups using the independent two-sample $t$-test. Proportions and grades were compared using the chi-square test and Kruskal-Wallis rank sum test, respectively. Two-tailed $\mathrm{P}<0.05$ was considered significant.

\section{Results}

All patients underwent surgery successfully without spinal cord injury or aggravation of neurological symptoms. Mean follow-up was $22.9 \pm 4.3$ months (range, 14-32). No screw loosening, titanium plate displacement, fracture, or laminar collapse occurred during the follow-up period. There were no significant differences in operative time, intra-operative blood loss, lamina open angles, or spinal cord drift distance between the groups $(P>0.05)$ (Table 2).

Cervical ROM in each group did not significantly change after surgery when compared with the preoperative level $(P>0.05)$. In group $B$, the CSA and cross-sectional area of the posterior cervical muscles significantly decreased after surgery $(P<0.05)$, while in group $A$, the changes were not significant $(P>0.05)$ (Table 3). 
The JOA score significantly increased in both groups after surgery $(P<0.05)$, and the neurological recovery rates were similar $(62.7 \%$ vs. $63.4 \%)(P>0.05)$. The AS in group $B$ was significantly more severe than the figure in group $A(P<0.05)($ Table 4$)$.

\section{Discussion}

The posterior cervical muscle-ligament complex is an important structure for maintaining the stability of the cervical vertebrae. It is mainly composed of the spinous processes, supraspinous ligament, interspinous ligaments, and muscle tissues attached to the spinous processes and plays an important role in maintaining the biomechanical stability and physiological curvature of the cervical spine [14]. During open-door laminoplasty, pruning or excision of the spinous processes causes damage to the supraspinous ligament and interspinous ligaments and also removes the spinal attachment points of the posterior cervical muscles. Destruction of the muscle-ligament complex and the loss of muscle attachment points can result in atrophy of the posterior cervical muscles and weakening of the tension band can lead to a loss of cervical curvature and even cervical kyphosis $[2,7,9,15]$. When performing open-door laminoplasty at C3-7, in order to fully expose the superior border of the C3 lamina and the ligamentum flavum between the $\mathrm{C} 2 / 3$ lamina, partial dissection of thesemispinalis cervicis from the $\mathrm{C} 2$ spinous process is required [6]. If this is not reconstructed properly at the end of the operation, iatrogenic muscle injury may result.

The semispinalis cervicis arises from the transverse process of the upper thoracic vertebrae and ends in the C2-5 spinous processes. From a physiological perspective, the most important point is its attachment to $\mathrm{C} 2$. Studies have shown that the semispinalis cervicis is the most important posterior cervical extensor muscle, as its contraction accounts for $37 \%$ of the total contraction distance in posterior cervical extension [7].Therefore, reconstruction of muscle attachment points and maintenance of mechanical strength of the muscle-ligament complex has become an area of investigation for spine surgeons seeking to improve outcomes after open-door cervical laminoplasty.

Cheng et al [16]. first split the extensor muscle attachment points from the $\mathrm{C} 2$ spinous process before opening the laminaeand then reattached the muscles to the $\mathrm{C} 2$ spinous process with a suture replacing wire in order to retain the integrity and mechanical strength of semispinalis cervicis. Umeda et al [17]. described C4-6 laminoplasty with C3 and C7 partial laminectomies or C3 laminectomy and C7 dome decompression to maintain the integrity of semispinalis cervicis and the nuchal ligament. Chen et al [18]. first isolated the muscle along the spinous process unilaterally to expose the laminae, and then cut off the muscle-ligament complex together with the spinous process from the root with piezosurgery; after the laminae were opened, the spinous process stump and muscle were reattached to the laminar cortex to preserve the unilateral paraspinal muscle complex. Although the above innovative techniques reconstruct and preserve the integrity of the posterior cervical muscles using different methods, they all increase the complexity of the operation. 
To solve this problem, we devised a simpler method of muscle attachment point reconstruction. The current centerpiece titanium plate used to fix the lamina to the lateral mass has a " $Z$ " shape with two holes at each end $[5,13,17-19]$. Considering that the root of the original spinous process is shifted to the contralateral side after the lamina is opened, it is difficult to achieve reconstruction of the muscle attachment points in the midline. Therefore, we modified the centerpiece titanium plate by appropriately extending the length of the titanium plate on the side of the lamina and adding a hole at the distal end (a total of three holes). During the operation, the medial two holes were used to fix the lamina, while the distal hole was used for reconstruction of the semispinalis cervicis and anchoring and suturing of the cervical extensor muscles.

We found no significant difference in operation time (136.7 $\mathrm{min}$ vs. $128.3 \mathrm{~min}$ ) or intra-operative blood loss $(275.9 \mathrm{ml}$ vs. $268.2 \mathrm{ml}$ ) between the study groups, indicating that the modified centerpiece titanium plate did not increase the complexity of the operation. In addition, postoperative neurological function significantly improved in both groups and the neurological recovery rates at last follow-up were similar. In addition, there was no significant loss of cervical ROM in either group after surgery. However, cervical curvature and cross-sectional area of the posterior cervical muscles remained well-maintained in group $A$ but significantly decreased in group $B$.

Retention of cervical motion segments and adequate stability reconstruction are the basis for maintaining normal cervical ROM $[14,16]$. A "Z-shaped" titanium plate has adequate strength and stiffness to allow stable reconstruction $[3,19]$. Lateral fixation allows each vertebral body to have independent motion function, so does not cause significant loss of cervical ROM [5,18-19]. Our modified centerpiece titanium plate provides a new attachment point for the posterior cervical muscles, thus avoiding muscle atrophy. In addition, the tension band generated by the posterior cervical muscles can still maintain cervical curvature. Moreover, the supporting point formed at the distal end of the titanium plate at the $\mathrm{C} 3$ and $\mathrm{C} 7$ segments can also increase the force arm length of the posterior cervical extensor muscles $[8,15,20]$. Muscle fatigue will not easily occur after frequent cervical flexion and extension, which may explain the mild AS reported by patients in group A.

AS are common after laminoplasty and occur in $6 \%-60 \%$ of patients [21]. The primary manifestations are postoperative neck and shoulder pain accompanied by neck muscle stiffness, tension, discomfort, soreness, or swelling $[3,5,7,12,14-15,20]$. The mechanisms of postoperative AS development remain unclear but may be related to posterior cervical muscle atrophy, change in cervical curvature or lamina open angle, injury of the muscle-ligament complex, joint capsule damage, cervical instability, or other factors $[2-5,7,9,12,14-21]$. Spine surgeons have tried to reduce AS by improving surgical technique $[2,7,9,12,15]$, preserving muscle attachment points $[7,9,17,22]$, reconstructing the muscle-ligament complex [18], implanting an appropriate internal fixation device [5], and prescribing postoperative rehabilitation exercises [23] and physical therapy [24]; however, all have achieved various results. In this study, although both groups were fixed with titanium plates with the same mechanical strength, the severity of AS was significantly lower in group A than group B. In addition, we found that the crosssectional area of the posterior cervical musculature decreased significantly after surgery in group B but 
not group A. These findings demonstrate that the third hole provided by the modified centerpiece titanium plate can not only reconstruct the integrity of the semispinalis cervicis, but also becomes an effective attachment point to provide mechanical support to the cervical extensor muscles. This effectively maintains the mechanical strength and tension band effect of the posterior cervical muscles, reducing the occurrence of AS.

Our study had several limitations. First, the clinical application time of the modified centerpiece mini-plate was short. Second, the number of samples included in the study was small, and there was a certain bias in the selection and grouping of patients. Third, the follow-up time was short. Therefore, to confirm the clinical efficacy, a large-scale, long-term, multicenter randomized controlled study is required.

\section{Conclusions}

We added a hole at the distal end for convenience in the reconstruction of the posterior cervical muscleligament complex on the basis of the conventional centerpiece plate. This procedure can maintain cervical curvature, significantly reduce the atrophy of posterior cervical muscles, and decrease the occurrence of AS without increasing the complexity of the operation.

\section{Abbreviations}

CSM: Cervical spondylotic myelopathy; ROM: Range of motion; ISI: Increased signal intensity;JOA: Japanese Orthopaedic Association; AS: Axial symptoms; CSA: Cervical spine angle; MLC: Muscle ligament complex

\section{Declarations}

\section{Acknowledgements}

We would like to thank all the participants in the studies.

\section{Authors' contributions}

LFJ and LYC performed the data collection, analyzed and interpreted the patient data, and wrote the manuscript. MJ performed background research for the topic, conducted the whole study, and prepared the manuscript for submission. ZZP performed the data collection. All authors read and approved the final manuscript.

\section{Funding}

None.

\section{Availability of data and materials}


The datasets analyzed during the current study are available from the corresponding author on reasonable request.

Ethics approval and consent to participate

All experimental protocols in this research were approved by the Ethics Committee of Tianjin hospital, and informed consent was obtained from all patients. The methods were carried out in accordance with the relevant guidelines, including any relevant details.

Consent for publication

Informed consent was obtained from all individual participants included in the study.

Competing interests

No benefits in any form have been or will be received from a commercial party related directly or indirectly to the subject of this manuscript.

\section{References}

1. Li Y, Yan X, Cui W, Zhang Y, et al. The effect of dural release on extended laminoplasty for the treatment of multi-level cervical myelopathy. BMC Musculoskelet Disord. 2019;20(1):181.

2. Li D, Hai Y, Meng X, et al. Posterior open-door laminoplasty secured with titanium miniplates vs anchors: a comparative study of clinical efficacy and cervical sagittal balance. J Orthop Surg Res. 2019;28;14(1):401.

3. Inui T, Inokuchi K, Watanabe Y, et al. Comparison of the operative time for open door laminoplasty using titanium plate spacers or hydroxyapatite block spacers: a retrospective study. J Orthop Surg Res. 2019;30;14(1):475.

4. Wang LN, Wang L, Song YM, et al. Clinical and radiographic outcome of unilateral opendoor laminoplasty with alternative levels centerpiece mini-plate fixation for cervical compressive myelopathy: a five-year follow-up study. Int Orthop. 2016;40(6):1267-74.

5. Hao XR, Zhao YB, Lu XD, et al. Comparison of the effects of different fixation methods on open-door side in posterior expansive open-door laminoplasty. Chin J Orthop. 2017;37(8):44956.

6. Lee BJ, Park JH, Jeon SR, et al. Importance of the preoperative cross-sectional area of the semispinalis cervicis as a risk factor for loss of lordosis after laminoplasty in patients with cervical spondylotic myelopathy. Eur Spine J. 2018;27(11):2720-8.

7. Takeuchi K, Yokoyama T, Aburakawa S, et al. Axial symptoms after cervical laminoplasty with C3 laminectomy compared with conventional C3-C7 laminoplasty: a modified laminoplasty preserving the semispinalis cervicis inserted into axis. Spine.2005;30(22): 25449. 
8. Healy AT, Lubelski D, West JL, et al. Biomechanics of open-door laminoplasty with and without preservation of posterior structures. J Neurosurg Spine. 2016;24(5):746-51.

9. Hosono N, Sakaura H, Mukai Y, et al. C3-6 laminoplasty takes over C3-7 laminoplasty with significantly lower incidence of axial neck pain. Eur Spine J. 2006;15(9):1375-9.

10. Harrison DE, Harrison DD, Cailliet R, et al. Cobb method or Harrison posterior tangent method: which to choose for lateral cervical radiographic analysis. Spine.2000;25(16): 2072-8.

11. Zhang Y, Li J, Li Y, et al. Incidence and risk factors of poor clinical outcomes in patients with cervical kyphosis after cervical surgery for spinal cord injury. Ther Clin Risk Manag. 2017;13:1563-8.

12.Zhao YJ, Cheng $\mathrm{C}$, Chen $\mathrm{HW}$, et al. Limited laminectomy and foraminal decompression combined with internal fixation for treating multi-segment cervical spondylotic myelopathy: Does it effectively improve neurological function and prevent C5 palsy? Medicine (Baltimore). 2018;97(47): e13327.

13. Kobayashi Y, Matsumaru S, Kuramoto, T et al. Plate fixation of expansive open-door laminoplasty decreases the incidence of postoperative C5 palsy. Clin Spine Surg. 2019;32(4):E177-82.

14. Lin S, Zhou F, Sun Y, et al. The severity of operative invasion to the posterior muscularligament complex influences cervical sagittal balance after open-door laminoplasty. Eur Spine J. 2015;24(1):127-35.

15. Kowatari K, Ueyama K, Sannohe A, et al. Preserving the $\mathrm{C7}$ spinous process with its muscles attached: effect on axial symptoms after cervical laminoplasty. J Orthop Sci. 2009;14(3):279-84.

16.Cheng Z, Chen W, Yan S, et al. Expansive open-door cervical laminoplasty: in situ reconstruction of extensor muscle insertion on the $\mathrm{C} 2$ Spinous process combined with titanium miniplates internal fixation. Medicine (Baltimore). 2015;94(28): e1171.

17.Umeda M, Sasai K, Kushida T, et al. A less-invasive cervical laminoplasty for spondylotic myelopathy that preserves the semispinalis cervicis muscles and nuchal ligament. $\mathrm{J}$ Neurosurg Spine. 2013;18(6):545-52.

18. Chen C, Yang C, Yang SH, et al. Clinical effect of modified open-door laminoplasty with preservation of the unilateral paraspinal muscle ligament complex in treating ossification of posterior longitudinal ligament of the cervical spine. Chin J Orthop. 2018;38(24):1511-21.

19. Yang Z, Liu C, Lin Y, et al. Comparative effectiveness of all levels miniplate fixation versus a modified hybrid fixation in cervical expansive open-door laminoplasty. Medicine (Baltimore). 2019;98(38):e16655.

20. Kato M, Nakamura H, Konishi S, et al. Effect of preserving paraspinal muscles on postoperative axial pain in the selective cervical laminoplasty. Spine. 2008;33(14):E455-9.

21. Ratliff JK, Cooper PR. Cervical laminoplasty: a critical review. J Neurosurg. 2003;98 (3 Suppl):230-8. 
22.Sakaura $\mathrm{H}$, Hosono N, Mukai Y, et al. Preservation of muscles attached to the $\mathrm{C} 2$ and $\mathrm{C7}$ spinous processes rather than subaxial deep extensors reduces adverse effects after cervical laminoplasty. Spine. 2010;35(16):E782-6.

23. Kawaguchi $Y$, Kanamori $M$, Ishiara $H$, et al. Preventive measures for axial symptoms following cervical laminoplasty. J Spinal Disord Tech. 2003;16(6):497-501.

24. Hansen IR, Søgaard K, Christensen R, et al. Neck exercises, physical and cognitive behavioural-graded activity as a treatment for adult whiplash patients with chronic neck pain: design of a randomised controlled trial. BMC Musculoskelet Disord. 2011;12:274.

\section{Tables}

Table 1. Comparison of patient characteristics between the two study groups

\begin{tabular}{|c|c|c|c|c|c|}
\hline & & $\begin{array}{l}\text { Group } \\
\text { A }\end{array}$ & $\begin{array}{l}\text { Group } \\
\text { B }\end{array}$ & $\begin{array}{l}t / X^{2} \\
\text { value }\end{array}$ & $\begin{array}{l}\mathrm{P} \\
\text { value }\end{array}$ \\
\hline & & $\begin{array}{l}\text { (37 } \\
\text { cases) }\end{array}$ & $\begin{array}{l}\text { (32 } \\
\text { cases) }\end{array}$ & & \\
\hline Sex & Male & 20 & 15 & 0.354 & 0.552 \\
\hline & Female & 17 & 17 & & \\
\hline Age (years) & & $\begin{array}{l}63.7 \pm \\
15.3\end{array}$ & $\begin{array}{l}62.5 \pm \\
14.4\end{array}$ & 0.333 & 0.739 \\
\hline Disease cou & e (months) & $\begin{array}{l}19.9 \pm \\
5.1\end{array}$ & $\begin{array}{l}18.7 \pm \\
4.9\end{array}$ & 0.992 & 0.325 \\
\hline Follow-up pe & od (months) & $\begin{array}{l}16.3 \pm \\
3.8\end{array}$ & $\begin{array}{l}17.2 \pm \\
4.0\end{array}$ & 0.957 & 0.342 \\
\hline$|S|$ & Yes & 24 & 20 & 0.042 & 0.839 \\
\hline & No & 13 & 12 & & \\
\hline Pathogenic & Cervical disc herniation & 19 & 15 & 0.548 & 0.908 \\
\hline & Ligamentum flavum hypertrophy & 3 & 4 & & \\
\hline & $\begin{array}{l}\text { Cervical disc herniation with ligamentum } \\
\text { flavum hypertrophy }\end{array}$ & 9 & 8 & & \\
\hline & Developmental spinal stenosis & 6 & 5 & & \\
\hline
\end{tabular}

ISI, increased signal intensity

Table 2. Comparison of operative and postoperative outcomes between the two groups 


\begin{tabular}{|lllll|}
\hline Group & $\begin{array}{l}\text { Operative time } \\
(\mathrm{min})\end{array}$ & $\begin{array}{l}\text { Intraoperative blood } \\
\text { loss }(\mathrm{ml})\end{array}$ & $\begin{array}{l}\text { Lamina open } \\
\text { angles }\left(^{\circ}\right)\end{array}$ & $\begin{array}{l}\text { Spinal cord drift } \\
\text { distance }(\mathrm{mm})\end{array}$ \\
$\begin{array}{l}\text { Group } \\
\text { A }\end{array}$ & $136.7 \pm 23.9$ & $275.9 \pm 33.1$ & $41.2 \pm 4.5$ & $2.4 \pm 0.3$ \\
$\begin{array}{l}37 \\
\text { cases })\end{array}$ & & & & \\
$\begin{array}{l}\text { Group } \\
\text { B }\end{array}$ & & & & \\
$\begin{array}{l}\text { (32 } \\
\text { cases })\end{array}$ & & & & \\
& $128.3 \pm 21.5$ & $268.2 \pm 31.6$ & $39.4 \pm 4.1$ & $2.3 \pm 0.4$ \\
t value & 1.525 & 0.984 & 1.726 & 1.184 \\
\hline p value & 0.132 & 0.548 & 0.328 & 0.240 \\
\hline
\end{tabular}

Note $\rrbracket^{*}$ Compared with before surgery, $\mathrm{P}<0.05$

Table 3. Comparison of muscle area, range of motion, and cervical spine angle between the two groups

\begin{tabular}{|c|c|c|c|c|c|c|c|c|}
\hline \multirow[t]{2}{*}{ Group } & \multicolumn{2}{|c|}{$\begin{array}{l}\text { Cross-sectional area of } \\
\text { posterior muscles } \\
\text { cervical muscles }\left(\mathrm{cm}^{2}\right)\end{array}$} & \multicolumn{3}{|c|}{$\operatorname{ROM}\left({ }^{\circ}\right)$} & \multicolumn{3}{|c|}{$\operatorname{CSA}\left({ }^{\circ}\right)$} \\
\hline & preop & $\begin{array}{l}\text { Final follow-up } \\
\text { postop }\end{array}$ & preop & $\begin{array}{l}3 \text { months } \\
\text { postop }\end{array}$ & $\begin{array}{l}\text { Final } \\
\text { follow- } \\
\text { up }\end{array}$ & preop & $\begin{array}{l}3 \\
\text { months } \\
\text { postop }\end{array}$ & $\begin{array}{l}\text { Final } \\
\text { follow- } \\
\text { up }\end{array}$ \\
\hline $\begin{array}{l}\text { Group } \\
\text { A } \\
\text { (37 } \\
\text { cases) }\end{array}$ & $\begin{array}{l}35.9 \pm \\
5.1\end{array}$ & $34.1 \pm 4.6$ & $\begin{array}{l}51.3 \\
\pm 5.2\end{array}$ & $\begin{array}{l}48.4 \pm \\
4.8\end{array}$ & $\begin{array}{l}49.5 \pm \\
5.0\end{array}$ & $\begin{array}{l}20.6 \\
\pm 2.5\end{array}$ & $\begin{array}{l}18.5 \pm \\
2.3\end{array}$ & $\begin{array}{l}20.4 \pm \\
2.6\end{array}$ \\
\hline $\begin{array}{l}\text { Group } \\
\text { B } \\
\text { (32 } \\
\text { cases) }\end{array}$ & $\begin{array}{l}35.2 \pm \\
4.9\end{array}$ & $31.0 \pm 4.1^{*}$ & $\begin{array}{l}50.6 \\
\pm 4.9\end{array}$ & $\begin{array}{l}47.4 \pm \\
4.6\end{array}$ & $\begin{array}{l}48.6 \pm \\
4.7\end{array}$ & $\begin{array}{l}21.7 \\
\pm 2.8\end{array}$ & $\begin{array}{l}17.1 \pm \\
2.0^{\star}\end{array}$ & $\begin{array}{l}18.3 \pm \\
2.1^{*}\end{array}$ \\
\hline t value & 0.579 & 2.934 & 1.135 & 1.636 & 0.792 & 1.711 & 2.677 & 3.652 \\
\hline $\begin{array}{l}P \\
\text { value }\end{array}$ & 0.564 & 0.004 & 0.260 & 0.106 & 0.431 & 0.092 & 0.009 & $<0.001$ \\
\hline
\end{tabular}

ROM, range of motion; CSA, cervical spine angle

Note ${ }^{*}$ Compared with before surgery, $\mathrm{P}<0.05$ 
Table 4. Comparison of AS classification and JOA score between the two groups

\begin{tabular}{|c|c|c|c|c|c|c|c|}
\hline \multirow[t]{2}{*}{ Group } & \multicolumn{3}{|c|}{ AS classification } & \multicolumn{3}{|c|}{ JOA score } & \multirow{2}{*}{$\begin{array}{l}\text { Recovery rate } \\
(\%)\end{array}$} \\
\hline & Severe & Moderate & Mild & Preop & $\begin{array}{l}3 \text { months } \\
\text { postop }\end{array}$ & $\begin{array}{l}\text { Final follow- } \\
\text { up }\end{array}$ & \\
\hline $\begin{array}{l}\text { Group A } \\
\text { (37 } \\
\text { cases) }\end{array}$ & 2 & 8 & 27 & $\begin{array}{l}7.5 \pm \\
2.0\end{array}$ & $12.3 \pm 3.1^{*}$ & $13.5 \pm 3.5^{\star}$ & $62.7 \pm 13.8$ \\
\hline $\begin{array}{l}\text { Group B } \\
\text { (32 } \\
\text { cases) }\end{array}$ & 3 & 15 & 14 & $\begin{array}{l}7.7 \pm \\
2.3\end{array}$ & $12.5 \pm 3.2^{*}$ & $13.6 \pm 3.4^{*}$ & $63.4 \pm 14.1$ \\
\hline $\mathrm{Z} / \mathrm{t}$ value & -2.357 & & & 0.382 & 0.263 & 0.119 & 0.208 \\
\hline$p$ value & 0.018 & & & 0.703 & 0.793 & 0.904 & 0.835 \\
\hline
\end{tabular}

AS, axial symptoms; JOA, Japanese Orthopedic Association

Note ${ }^{*}$ Compared with before surgery, $\mathrm{P}<0.05$

\section{Figures}




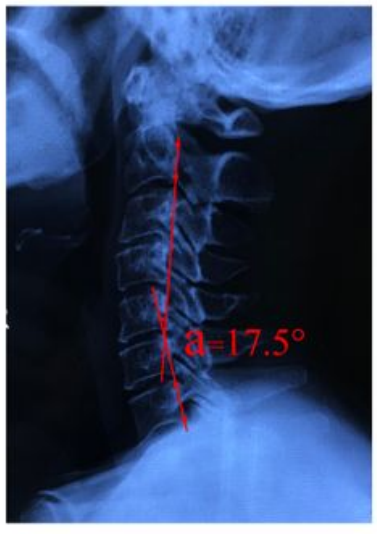

A

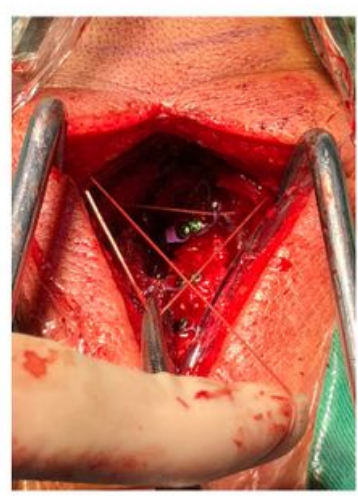

E

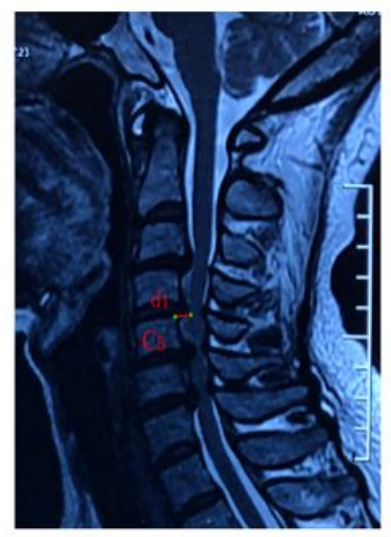

B

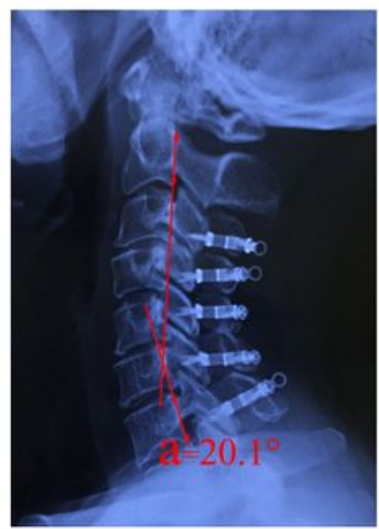

$\mathbf{F}$

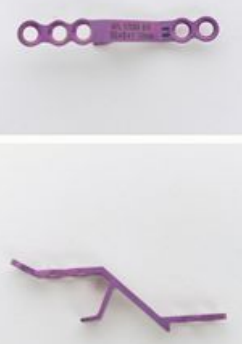

C

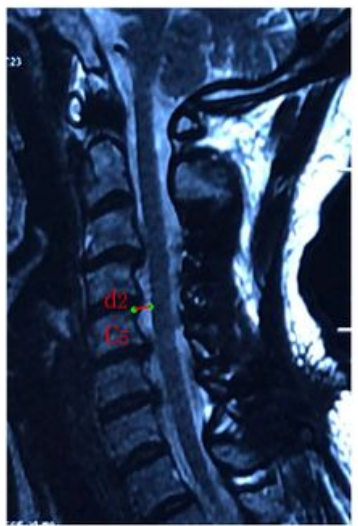

G

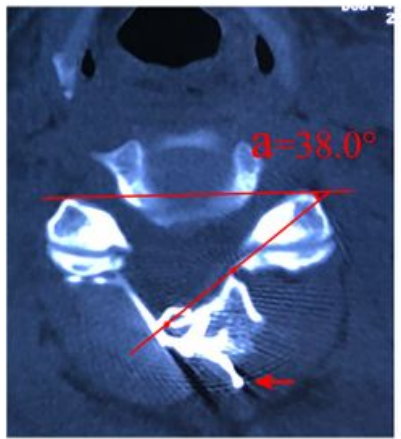

D

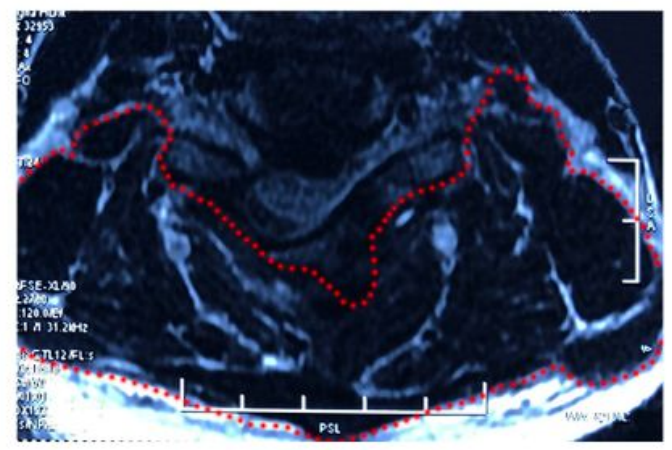

H

\section{Figure 1}

A 59-year-old male patient presented with numbness in the limbs and walking asthenia for 20 months. A: Preoperative plain radiography showed hyperosteogeny at the anterior and posterior margins of the cervical vertebrae (cervical spine angle $(C S A)=17.5^{\circ}$ ). B: Sagittal magnetic resonance imaging (MRI) showed disc herniations at the C3-7 segments with ligamentum flavum hypertrophy; the spinal cord was compressed and appeared "beaded." C: Front and side images of the modified centerpiece titanium plate. D: Postoperative computed tomography showed the C3 lamina open angle was $38.0^{\circ}$; the preformed hole (red arrow) was used to suture the posterior cervical muscles. E: Rebuilding of the posterior cervical muscles to the reserved additional hole; F: Plain radiography 1 year after the operation showed the opendoor laminoplasty with modified centerpiece plates at C3, C4, and C7 (CSA $\left.=20.1^{\circ}\right) . \mathrm{G}-\mathrm{H}$ : Postoperative MRI showed the spinal canal was open with adequate decompression and sufficient spinal cord posterior drift. The cross-sectional area of posterior cervical muscles was $34.7 \mathrm{~cm} 2$. 


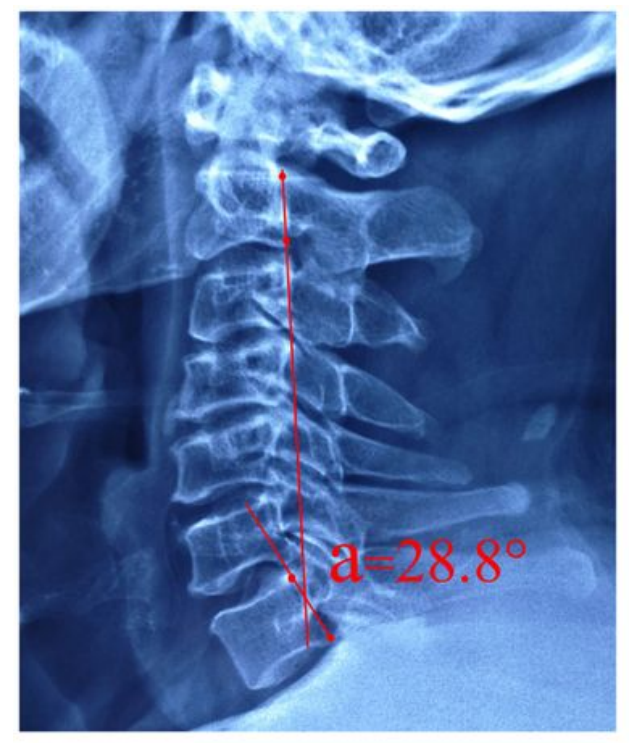

A

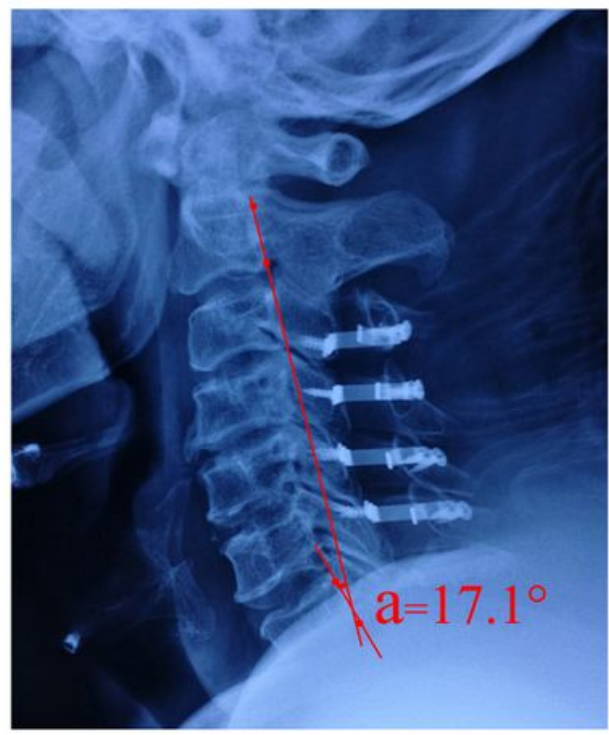

D

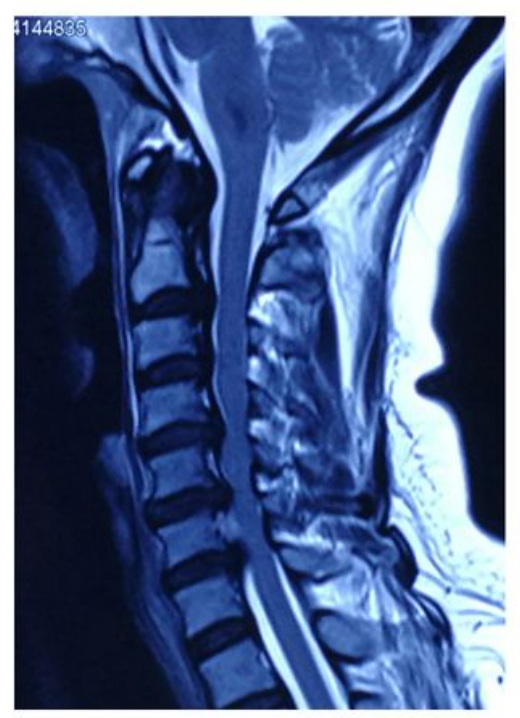

B

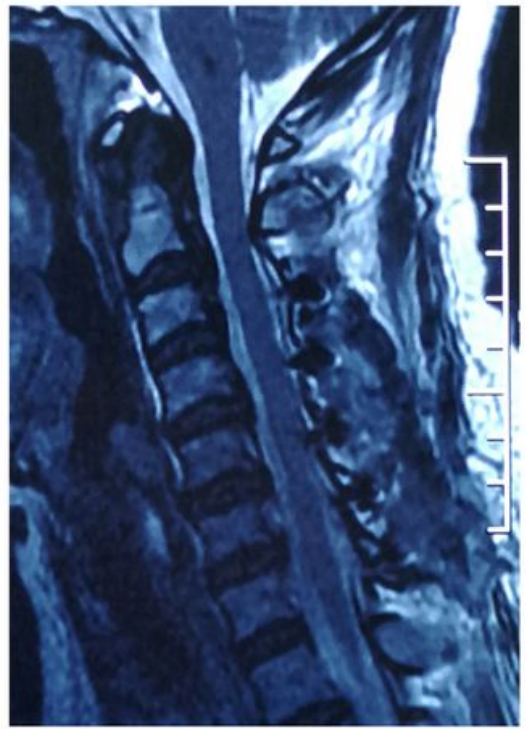

E

\section{Figure 2}

A 61-year-old female patient presented with numbness in the upper limbs and asthenia for 18 months. A: Preoperative plain radiography showed degenerative changes of the cervical vertebrae (cervical spine angle $\left.(\mathrm{CSA})=28.8^{\circ}\right)$. B: Preoperative magnetic resonance imaging $(\mathrm{MRI})$ showed cervical disc herniation at the $\mathrm{C} 2-7$ segments and multi-segmental spinal cord compression. C: Postoperative computed tomography showed the lamina open angle at $\mathrm{C} 4$ was $43.9^{\circ}$. D: Plain radiography 1 year after the operation showed the laminoplasty with conventional centerpiece titanium plate at the C3-7 segments $\left(\mathrm{CSA}=17 \cdot 1^{\circ}\right)$ E: Postoperative MRI showed an adequate decompression and significant posterior spinal cord drift. 